\title{
Prevalence of overweight and obesity and associated risk factors in urban primary-school children in Babol, Islamic Republic of Iran
}

K.O. Hajian-Tilaki, ${ }^{1}$ P. Sajjadi ${ }^{1}$ and A. Razavi ${ }^{1}$

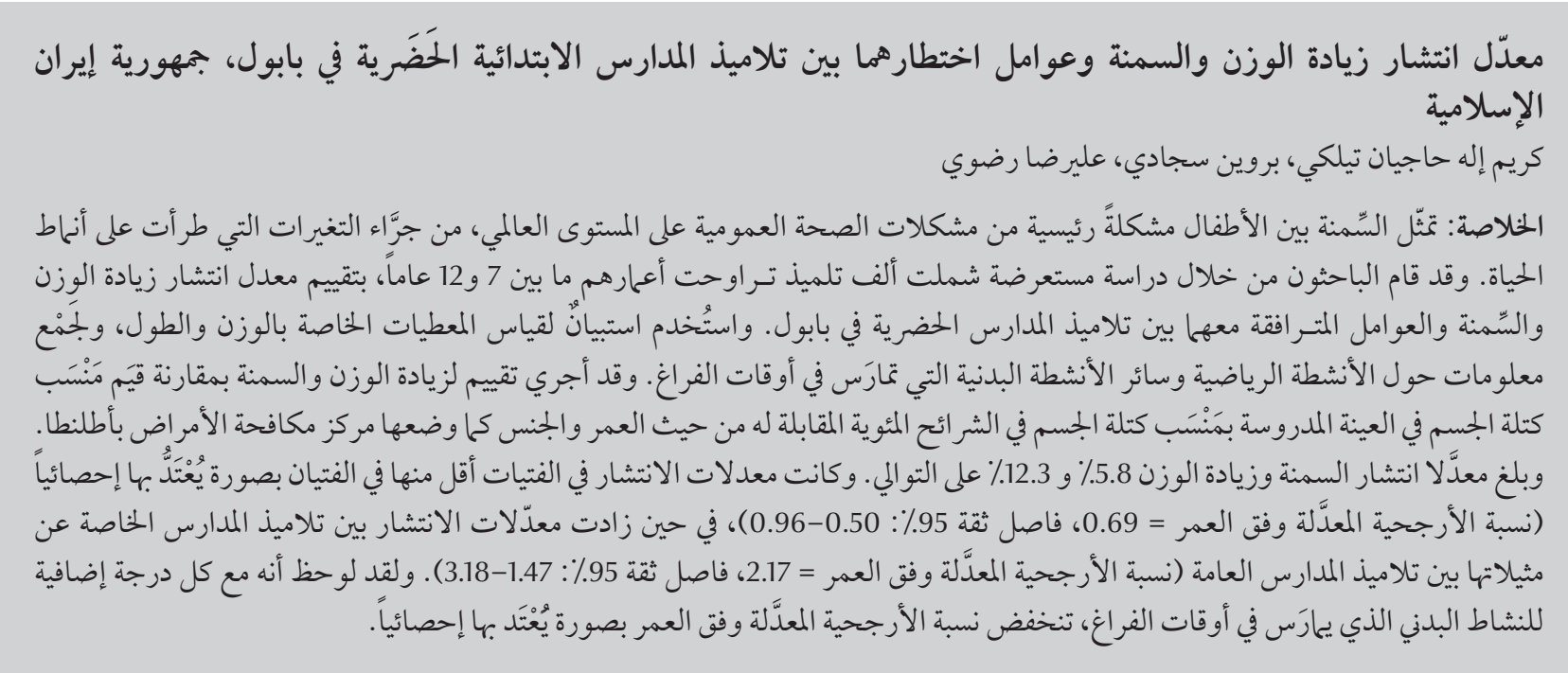

ABSTRACT Childhood obesity is a major public health problem globally because of changes in lifestyles. We assessed the prevalence of overweight/obesity and associated factors in urban schoolchildren in Babol in a crosssectional study of 1000 schoolchildren aged 7-12 years. Weight and height were measured and data on sports activities and leisure time physical activities were collected by questionnaire. Overweight/obesity were assessed by comparing body mass index (BMI) values to the BMI index for age and sex percentiles set by CDC, Atlanta. The prevalence of obesity and overweight was $5.8 \%$ and $12.3 \%$ respectively. The prevalence was significantly lower in girls compared with boys (age-adjusted $\mathrm{OR}=0.69,95 \% \mathrm{Cl}: 0.50-0.96$ ) and higher among private-school educated children compared with public-school educated students (age adjusted OR = 2.17, 95\% Cl: 1.47-3.18). For each additional score of leisure time physical activity, the age-adjusted OR decreased significantly.

Prévalence de la surcharge pondérale, de l'obésité et des facteurs de risque associés chez des écoliers du primaire en environnement urbain à Babol (République islamique d'Iran)

RÉSUMÉ L'obésité de l'enfant est un problème de santé publique majeur dans le monde, en raison des modifications des modes de vie. Nous avons évalué la prévalence de la surcharge pondérale/de l'obésité et les facteurs associés chez des écoliers en environnement urbain à Babol, dans une étude transversale portant sur 1000 enfants âgés de sept à douze ans. Les données relatives au poids et à la taille, aux activités sportives et aux activités physiques pendant le temps de loisirs ont été recueillies par questionnaire. La surcharge pondérale/ l'obésité ont été évaluées en comparant les valeurs de l'indice de masse corporelle à l'indice de masse corporelle en fonction des percentiles pour l'âge et le sexe définis par le CDC d'Atlanta. La prévalence de l'obésité et de la surcharge pondérale était de 5,8 \% et 12,3\%, respectivement. La prévalence était significativement plus faible chez les filles par rapport aux garçons (OR ajusté sur l'âge = 0,69; IC à $95 \%$ : 0,50-0,96) et plus importante chez les enfants des écoles privées par rapport à la prévalence dans les écoles publiques (OR ajusté sur l'âge $=2,17$; IC à $95 \%$ : 1,47-3,18). Pour chaque score supplémentaire d'activité physique pendant le temps de loisirs, l'OR ajusté sur l'âge diminuait considérablement. 


\section{Introduction}

In the past decade, overweight and obesity among children has become a major public health problem in developed and developing countries [1-3]. Adverse outcomes of overweight and obesity include psychological and physical effects during childhood and also increased risk of adult obesity, which is a major independent risk factor for cardiovascular diseases, diabetes, hypertension and cancers [2].

The increasing rates are a result of changing lifestyles and industrialization with the associated increasing rate of television viewing and playing with computer games, consumption of high calorie and high fat foods coupled with low levels of energy expenditure in the form of low physical activity [3]. In the United States of America (USA), the average rates for overweight and obesity among children have been reported to be $22 \%$ and $11 \%$ respectively, while in the state of Carolina, it was $32.4 \%$ and $16.4 \%$ respectively [2]. Figures for overweight and obesity for Spain and Italy were $40 \%$, and for Canada $25.3 \%$ [4-6].

This epidemic of childhood overweight is worldwide; in particular some Middle East and Asian countries have documented a significant increasing rate in the past decade [7-12]. In the Islamic Republic of Iran it has been reported that the prevalence of overweight has been increasing in the country [13], but there is little published information.

There is an increasing rate of urbanization and changing lifestyles in the north of the Islamic Republic of Iran, which carries the risk of increased overweight and obesity in children. Because of the lack of information on the health status of school-aged children in the north of the country, this study was conducted to determine the prevalence of childhood obesity and overweight and the association with demographic, social and lifestyle factors.

\section{Methods}

This was a cross-sectional study with a sample of 1000 primary-school children aged 7 to 12 years living in urban areas of Babol, northern Islamic Republic of Iran in 2006. The study proposal was approved by the research and ethical committee of Babol University of Medical Sciences and an informed consent was obtained from all parents prior to participation of children in the study.

Assuming 15\% obesity/overweight [13] with a confidence level of $95 \%$ and maximum marginal error of about 0.02 , the sample size was calculated as 1000. A cluster sampling techniques was carried out with 20 schools (11 for girls and 9 for boys) of 100 as clusters of equal size of 50 subjects. At the first step of sampling, 20 schools were selected by proportional probability using a systematic sampling technique based on the cumulative frequency of the total number of students in each school, both public and private for both sexes (i.e. giving more weight to schools with a greater number of students). In the second stage, within each selected school, for each grade, we randomly recruited 10 healthy students aged 7-12 years; thus, for 5 grades in each school, 50 students were included.

Students with any organic health problems or systemic disease were excluded. The students selected were in apparently good health, with no known systemic or debilitating conditions according to the student health records for the annual clinical examination. There were no refusals to participate.

Interviews using the Baeke questionnaire were carried out in school by trained nursing students and school health care-givers. All the schools under study were covered for health care by the Ministry of Health and the Ministry of Education, and each student had health records which included demographic data that was updated annually. For students of the 1st and 2nd grades, who were not able to answer the demographic data such as parents' education status, we also used information from the school health records. After an interview and a review of clinical examination records, height and weight were measured. Body weight was assessed using a digital Seca scale while the children were wearing light clothing with no shoes. Standing height was measured without shoes using a portable stadiometer. The reliability of measurements of height and weight were assessed by repeated measurements on the same student with an intra-class correlation coefficient of $>0.95$. Body mass index (BMI) was calculated as weight $(\mathrm{kg})$ divided by the square of the height $(\mathrm{m})\left(\mathrm{kg} / \mathrm{m}^{2}\right)$. The demographic and lifestyle data, in particular age, sex, type of school (public/private), family size, birth order, parental educational level and occupation, number of hours of television watching and playing with computer games per day, were collected by interview and the review of students' files. Data on sports physical activities and leisure time physical activities were collected with a standard Baecke questionnaire on a 5-point scale [14] and the activity indices were calculated using the Baecke formula [15]. Briefly, activity/ sport intensity is divided into: low level with average energy expenditure 0.76 $\mathrm{MJ} / \mathrm{h}$; middle level with average energy expenditure $1.26 \mathrm{MJ} / \mathrm{h}$; and high level with average energy expenditure 1.76 $\mathrm{MJ} / \mathrm{h}$. The sport score was computed according to the formula, based on the intensity of the most frequent sport. The sport score was categorized on a 5 point scales. The sport index was calculated as the average value for the sport score and 3 other related parameters of leisure time sport activity. In addition, the leisure time index was computed as average value of 4 parameters related to leisure time physical activity.

The reliability of the questionnaire was assessed in a pilot study that yielded a Cronbach-alpha coefficient $>0.90$. Obesity, overweight and underweight 
were categorized according to the BMI index for age and sex percentiles set by the Centers for Disease Control and Prevention [16] in which BMI $\geq 95$ th percentile was regarded as obese; 85 th $\leq$ $\mathrm{BMI}<95$ th percentile as overweight and $\mathrm{BMI}<5$ th percentile as underweight; those with 5 th $\leq \mathrm{BMI}<85$ th percentile were categorized as normal.

\section{Statistical analysis}

In statistical analysis, we used SPSS, version 16.0 software. We computed the chi-squared test for bivariate data analysis and also used a logistic regression analysis to estimate the crude and age-adjusted odds ratios (ORs) and 95\% confidence intervals (CIs) for overweight and obesity for different demographic and lifestyle factors. A $P$ value $<0.05$ was considered statistically significant.

\section{Results}

The mean age of the students was 9.3 [standard deviation (SD) 1.5] years. Of the 1000 participants, $45 \%$ were male and $55 \%$ were female. The means for watching television and playing computer games were 2.25 (SD 1.3) and 0.32 (SD 0.66) hours per day respectively. The mean leisure time physical activity and sports activity scores were 2.55 (SD 0.62) and 2.88 (SD 0.72) respectively. Over half of the fathers of the children had an education level of high school or higher; $20.7 \%$ had a university-level education while only $1.8 \%$ were illiterate.

The mean BMIs (SD) for males and females were 16.8 (SD 3.4) $\mathrm{kg} / \mathrm{m}^{2}$ and $16.7(\mathrm{SD} 2.8) \mathrm{kg} / \mathrm{m}^{2}$ respectively; the difference was not statistically significant but in both sexes the mean BMI increased with age. Overall, the prevalence rates of obesity, overweight and underweight were $5.8 \%, 12.3 \%$ and $13.5 \%$ respectively. The rate of obesity and overweight increased after age 8 years but this was not statistically significant.
Table 1 shows that the prevalence of obesity and underweight was higher in males than females ( $8.8 \%$ versus $3.8 \%$ and $16.0 \%$ versus $11.8 \%$ respectively, $P$ $=0.001)$. In females, the prevalence of overweight increased with increasing age. The lowest obesity and overweight rates in females were $5.2 \%$ and $3.1 \%$ for girls aged 7 years.

Table 2 shows that the age-adjusted OR for overweight/obesity was significantly lower in females than males $(\mathrm{OR}=0.69,95 \% \mathrm{CI}: 0.51-0.96)$. Family size was associated with overweight/ obesity, the higher the family size the lower the odds of overweight/obesity but, birth order was not. Higher level of maternal education to university level was significantly positively associated with overweight/obesity compared with less educated and illiterate mothers $(\mathrm{OR}=2.43 ; 95 \% \mathrm{CI}: 1.01-5.96)$. However there was no significant association with fathers' education level. For the type of school, the prevalence of overweight/obesity was 2.17-fold (95\% CI: 1.47-3.18) greater in students from private schools compared with those from public schools $(P<0.001)$. Additionally, there was an inverse relation between the risk of overweight/obesity and leisure time physical activity score. For each additional score of leisure time physical activity, the risk of overweigh/ obesity significantly decreased (ageadjusted OR $=0.73,95 \%$ CI: 0.56-0.96, $P<0.05)$ but the association between sports activity index and obesity/overweight was not statistically significant.

\section{Discussion}

The findings of the present study indicate an overall prevalence rate of $5.8 \%$ for obesity and $12.3 \%$ for overweight and $18.1 \%$ for both obesity and overweight in children aged 7-12 years living in urban areas in the north of the Islamic Republic of Iran. The prevalence of overweight/obesity was greater in private school students compared with public school students, while the prevalence of underweight was the opposite regarding type of school (data not shown in tables). The mean BMI for boys and girls was similar.

The results of our study are similar to the results reported from other geographic areas of the Islamic Republic of Iran. In a study in the west of the country, the prevalence of obesity in schoolchildren aged 7-12 years was $9.9 \%$ [14]. In another study in primary school girls in Tehran, the prevalence of overweight and obesity was $13.2 \%$ and $7.7 \%$ respectively [13].

The prevalence of obesity and overweight in other parts of the worlds varies quite considerably. Some studies report higher rates than ours. For example, Krassas et al. reported the prevalence of overweight in 2001 in Greek children aged 6-10 years was $25.3 \%$ [17]. In addition, Núñez-Rivas et al. in Costa Rica reported that the prevalence of overweight and obesity in children aged $7-12$ years was $34.5 \%$ and $26.2 \%$ respectively [18]. In Qatar the prevalence of overweight in boys was $28.6 \%$ and in girls was 18.9\% [11] while in Kuwait it was $30.0 \%$ in boys and $31.8 \%$ in girls [12]. In a study by Manzoli et al in 2005 in Italy, the prevalence of overweight in students aged $6-16$ years was $40.6 \%$ [19] and in Spain it was 40.0\% [4]. In the USA, the prevalence of overweight and obesity among children has been reported to be $22 \%$ and $11 \%$ respectively [2].

However some studies report similar or lower rates than ours. In India, the prevalence of overweight was reported as $10 \%$ among $10-15$ year-olds [9], and in Turkish students aged 12-17 years this figure was $10.6 \%$ [8]. In a study by Zini et al. in Malaysian primary-school children aged 9-10 years in 2005, the prevalence of overweight and obesity was $16.3 \%$ and $6.3 \%$ respectively [10], which only is slightly higher than our rates. The differences seen in the results of these studies may be attributed partially to the effect of genetic, lifestyle and 


\begin{tabular}{|c|c|c|c|c|c|c|c|c|}
\hline \multirow[t]{2}{*}{ Age (years) } & \multicolumn{2}{|c|}{$\begin{array}{l}\text { Underweight } \\
\text { (BMI < 5th) }\end{array}$} & \multicolumn{2}{|c|}{$\begin{array}{c}\text { Normal } \\
(5 \text { th } \leq \text { BMI }<85 \text { th })\end{array}$} & \multicolumn{2}{|c|}{$\begin{array}{c}\text { Overweight } \\
(\text { 85th } \leq \text { BMI }<\text { 95th })\end{array}$} & \multicolumn{2}{|c|}{$\begin{array}{c}\text { Obese } \\
(\mathrm{BMI} \geq \mathbf{9 5 \mathrm { th }})\end{array}$} \\
\hline & No. & $\%$ & No. & $\%$ & No. & $\%$ & No. & $\%$ \\
\hline \multicolumn{9}{|l|}{ Males } \\
\hline 7 & 12 & 15.8 & 46 & 60.5 & 13 & 17.1 & 5 & 6.6 \\
\hline 8 & 9 & 12.9 & 50 & 71.4 & 6 & 8.6 & 5 & 7.1 \\
\hline 9 & 9 & 12.5 & 42 & 58.3 & 12 & 16.7 & 9 & 10.9 \\
\hline 10 & 20 & 24.4 & 47 & 57.3 & 8 & 9.8 & 7 & 8.5 \\
\hline 11 & 6 & 9.8 & 42 & 68.9 & 5 & 8.2 & 8 & 13.1 \\
\hline 12 & 8 & 20.5 & 24 & 61.5 & 6 & 15.4 & 1 & 2.6 \\
\hline Total & 64 & 16.0 & 251 & 62.8 & 50 & 12.5 & 35 & 8.8 \\
\hline \multicolumn{9}{|l|}{ Females } \\
\hline 7 & 8 & 8.3 & 80 & 83.3 & 5 & 5.2 & 3 & 3.1 \\
\hline 8 & 15 & 14.3 & 78 & 83.3 & 6 & 5.7 & 6 & 5.7 \\
\hline 9 & 14 & 12.4 & 78 & 74.3 & 15 & 13.3 & 6 & 5.3 \\
\hline 10 & 9 & 8.3 & 76 & 70.4 & 19 & 17.6 & 4 & 3.7 \\
\hline 11 & 13 & 9.8 & 95 & 71.4 & 22 & 16.5 & 3 & 2.3 \\
\hline 12 & 12 & 26.7 & 26 & 57.8 & 6 & 13.3 & 1 & 2.2 \\
\hline Total & 71 & 11.8 & 433 & 72.2 & 73 & 12.2 & 23 & 3.8 \\
\hline
\end{tabular}

$B M I=$ body mass index .

environmental factors, and variations in the age groups of the samples and because of different study methods and definitions of obesity and underweight across the various studies. The prevalence of overweight/obesity was greater than underweight, and this suggests that the Islamic Republic of Iran is in a transitional state of increasing childhood overweight and obesity, such as is happening in Middle Eastern and Asian countries because of changes in urbanization and lifestyle in recent years.

In our study, because of the narrow age range studied ( $7-12$ years), we did not observe a significant association between age and BMI status with respect to CDC standard percentiles for age and sex. Nonetheless, the prevalence of obesity and overweight in female children tended to increase significantly with age and the mean BMI tended to increase with age in both sexes. In a study in Mexican children aged 10-17 years, the prevalence of obesity with respect to age varied from $9.2 \%$ to $14.7 \%$ and $6.8 \%$ to $10.6 \%$ in females and males respectively [20].
We found prevalence rates of obesity and underweight were significantly greater in boys than girls. Similarly Krasass et al. found the prevalence of obesity was significantly higher in males than females [7], as did Langendijk et al. in northern Thailand among children aged 7-9 years [21]. In some published studies, the prevalence of obesity and underweight was similar in males and females [22] and in other studies these rates were greater in females [23]. The differences in pattern of obesity and underweight between the sexes may be explained by the different patterns of growth with respect to age and sex, to the different nutritional behaviour or to other lifestyle-related factors between the two sexes. The differences might in part be explained by different study methods and definition of obesity and underweight across various studies.

The association between obesity and overweight and fathers' occupation and education was not statistically significant in our study although the rates tended to be higher for those with higher than high-school education. On logistic regression analysis, the risk of obesity and overweight was significantly (2.2 times) higher in private school students compared with public school students. In contrast, the prevalence of underweight was more common in public school children. If registration of students in private schools is considered as a proxy for high socioeconomic status of their families, the risk of overweight and obesity is thus greater in children from a high socioeconomic background while the prevalence of underweight is higher in families of lower socioeconomic status. These findings accord with previously published studies $[24,25]$ that demonstrate the effect of socioeconomic factors on growth status of children. In relation to family size and birth order, the prevalence of overweight and obesity was lower in children with a family size of 5 or more. In addition, in only children (no siblings) the odds of obesity and overweight tended to be elevated. The association between family size and underweight was also observed in a study by Gur et al. among Turkish children [18]. 


\begin{tabular}{|c|c|c|}
\hline Variable & Crude OR (95\% CI) & Age-adjusted OR (95\% Cl) \\
\hline \multicolumn{3}{|l|}{ Age group (years) } \\
\hline 7 & 1.0 & - \\
\hline 8 & $0.85(0.46-1.55)$ & - \\
\hline 9 & $1.65(0.96-2.83)$ & - \\
\hline 10 & $1.40(0.81-2.42)$ & - \\
\hline 11 & $1.27(0.79-2.36)$ & - \\
\hline 12 & $1.12(0.55-2.28)$ & - \\
\hline \multicolumn{3}{|l|}{ Sex } \\
\hline Male & 1.0 & 1.0 \\
\hline Female & $0.70(0.51-0.98)^{*}$ & $0.69(0.50-0.96)^{*}$ \\
\hline \multicolumn{3}{|l|}{ Mothers'education } \\
\hline Illiterate or primary level & 1.0 & 1.0 \\
\hline Elementary level & $2.34(1.0-5.48)^{*}$ & $2.21(0.94-5.21)$ \\
\hline High school level & $1.88(0.82-4.34)$ & $1.78(0.77-4.12)$ \\
\hline College level & $1.60(0.69-3.74)$ & $1.51(0.69-3.53)$ \\
\hline University level & $2.43(1.01-5.90)^{*}$ & $2.45(1.01-5.96)^{*}$ \\
\hline \multicolumn{3}{|l|}{ Fathers'education } \\
\hline Illiterate or primary level & 1.0 & 1.0 \\
\hline Elementary level & $1.33(0.57-3.1)$ & $1.20(0.51-1.83)$ \\
\hline High school level & $1.09(0.48-2.46)$ & $0.98(0.43-2.23)$ \\
\hline College level & $1.42(0.63-3.130$ & $1.28(0.57-2.91)$ \\
\hline University level & $1.62(0.71-3.62)$ & $1.51(0.66-3.46)$ \\
\hline \multicolumn{3}{|l|}{ Family size } \\
\hline$\leq 3$ & 1.0 & 1.0 \\
\hline 4 & $0.84(0.53-1.33)$ & $0.77(0.48-1.23)$ \\
\hline 5 & $0.55(0.32-0.95)$ & $0.51(0.29-0.88)^{*}$ \\
\hline$\geq 6$ & $0.64(0.33-1.26)$ & $0.59(0.30-1.17)$ \\
\hline \multicolumn{3}{|l|}{ Birth order } \\
\hline 1 & 1.0 & 1.0 \\
\hline 2 & $0.89(0.62-1.28)$ & $0.90(0.63-1.29)$ \\
\hline 3 & $0.67(0.40-1.14)$ & $0.68(0.40-1.16)$ \\
\hline$\geq 4$ & $0.72(0.35-1.47)$ & $0.72(0.35-1.48)$ \\
\hline \multicolumn{3}{|l|}{ Type of school } \\
\hline Public & 1.0 & 1.0 \\
\hline Private & $2.14(1.46-3.13)^{* * *}$ & $2.17(1.47-3.18)^{* * *}$ \\
\hline $\begin{array}{l}\text { Leisure time physical activity } \\
\text { index (each additional score) }\end{array}$ & $0.78(0.60-1.02)$ & $0.73(0.56-0.96)^{*}$ \\
\hline $\begin{array}{l}\text { Sport activity index (each } \\
\text { additional score) }\end{array}$ & $1.12(0.89-1.41)$ & $1.13(0.91-1.42)$ \\
\hline
\end{tabular}

${ }^{*} P<0.05 ;{ }^{* * *} P<0.001$.

The significant negative association between leisure time physical activity index and obesity/overweight as shown in this study has also been observed in studies from other countries [26-29].
However, the association between sport activity index and obesity risk was not significant in our study. The lack of significant association between sport physical activity and obesity risk in our study may be due to uniformity of school programmes in sport physical activity for all students.

Our results do not show the factors examined to be the causes of overweight and obesity in children but they do demonstrate a significant association of these factors with overweight and obesity. A limitation of our study was the possibility of bias (interview bias and recall bias), especially with regard to television viewing, computer use and physical activity levels, which may affect the validity of the findings. However, we minimized such biases by similar instructions for the interviewers and by checking data with school records whenever the subjects were not able to answer in interview. Another limitation was the lack of data with respect to dietary intake which may be an important factor related to obesity and weight gain. We did not assess dietary intake because, given the cultural similarity, the uniformity of the diet in our urban area can be assumed, and also because this item is heavily subject to recall bias. In addition, since the lifestyle among children in rural areas might be different from those in urban areas, our findings can only be generalized to the children living in urban areas with similar age group, ethnic background and lifestyle.

In conclusion, a prevalence of overweight/obesity of $18.1 \%$, while not as high as in some countries, suggests that the Islamic Republic of Iran may be in a nutritional and epidemiological transition process toward increasing childhood obesity, and that multiple strategies and interventions are warranted to prevent overweight/obesityrelated risk behaviour in school-aged children.

\section{Acknowledgement}

The authors would like to thank the school health care givers and directors of Babol city for their helpful assistance in data collection. 


\section{References}

1. Dietz WH. Health consequences of obesity in youth: childhood predictors of adult disease. Pediatrics, 1998, 101:518-525.

2. Terrell DF. Overweight and obesity prevalence rates among youth in the Carolinas. North Carolina Medical Journal, 2002, 63:281-286.

3. Veugelers PJ, Fitzgerald AL. Prevalence of and risk factors for childhood overweight and obesity. Canadian Medical Association Journal, 2005, 173:607-613.

4. Martínez Vizcaíno V et al. Prevalencia de obesidad y tendencia de los factores de riesgo cardiovascular en escolares de 1992 a 2004 : estudio de Cuenca [Prevalence of obesity and trends in cardiovascular risk factors among Spanish school children, 1992-2004: the Cuenca (Spain) study]. Medicina Clínica, 2006, 126:681-685.

5. Baratta $\mathrm{R}$ et al. High prevalence of overweight and obesity in 11-15-year-old children from Sicily. Nutrition, Metabolism, and Cardiovascular Diseases, 2006, 16:249-255.

6. Canning PM, Courage ML, Frizzell LM. Prevalence of overweight and obesity in a provincial population of Canadian preschool children. Canadian Medical Association Journal, 2004, 171:240-242.

7. Krassas GE et al.; Balkan Group for the Study of Obesity. Prevalence of overweight and obesity among children and adolescents in Thessaloniki-Greece and Kayseri-Turkey. Pediatric Endocrinology Reviews; PER, 2004, 1(Suppl. 3):460-464.

8. Oner $\mathrm{N}$ et al. Prevalence of underweight, overweight and obesity in Turkish adolescents. Swiss Medical Weekly, 2004, 134(35-36):529-533.

9. Sidhu S, Marwah G, Prabhjot. Prevalence of overweight and obesity among the affluent adolescent school children of Amritsar, Punjab. Collegium Antropologicum, 2005, 29:53-55.

10. Zaini $\mathrm{MZ}$ et al. Factors affecting nutritional status of Malaysian primary school children. Asia-Pacific Journal of Public Health, 2005, 17:71-80.

11. Bener A. Prevalence of obesity, overweight, and underweight in Qatari adolescents. Food and Nutrition Bulletin, 2006, 27: 39-45.

12. Al-Isa AN. Body mass index, overweight and obesity among Kuwaiti intermediate school adolescents aged 10-14 years. European Journal of Clinical Nutrition, 2004, 58:1273-1277.

13. Mozafari $\mathrm{H}$, Nabaei B. [Prevalence of obesity and overweight in Tehranian girls' student of primary schools]. University Jahad Quarterly Publication of Health Sciences: (Tehran/Iran), 2002, 1(4):15-19 [in Farsi].

14. Shagholian N, Aein F, Dress F. [Determination of 90th percentiles of $\mathrm{BMI}$ and some risk factors of obesity in primary school children aged 7-12 years in the province of Jhaharmahal-Bakhtiary (Iran)]. Journal of Kord City University of Medical Science (Iran), 2003:5(4):42-48 [in Farsi].

15. Baecke JAH, Burema J, Frijters JE. A short questionnaire for the measurement of habitual physical activity in epidemio- logical studies. American Journal of Clinical Nutrition, 1982, 36:936-942.

16. CDC clinical growth charts. Atlanta, Georgia, Centers for Disease Control and Prevention, 2000 (http://www.cdc.gov/ growthcharts, accessed 22 December 2010).

17. Krassas GE et al. Prevalence and trends in overweight and obesity among children and adolescents in Thessaloniki, Greece. Journal of Pediatric Endocrinology \& Metabolism, 2001, 14(Suppl. 5):1319-1326, discussion 1365.

18. Núñez-Rivas HP et al. Prevalence of overweight and obesity among Costa Rican elementary school children. Revista Panamericana de Salud Publica, 2003, 13:24-32.

19. Manzoli L et al. Prevalenza di obesità, sovrapeso e ipertensione nei bambini e adolescenti della provincia di Pescara [Prevalence of obesity, overweight and hypertension in children and adolescents from Abruzzo, Italy]. Annali di igiene: medicina preventiva e di comunità, 2005, 17:419-431.

20. del Río-Navarro BE et al.; Encuesta Nacional de Salud 2000 Working Group, National Health Survey 2000. The high prevalence of overweight and obesity in Mexican children. Obesity Research, 2004, 12:215-223.

21. Langendijk $\mathrm{G}$ et al. The prevalence of childhood obesity in primary school children in urban Khon Kaen, northeast Thailand. Asia Pacific Journal of Clinical Nutrition, 2003, 12:66-72.

22. Malecka-Tendera E et al. Obesity and overweight prevalence in Polish 7 to 9-year-old children. Obesity Research, 2005, 13(6):964-968.

23. Tabatabaei $\mathrm{M}$ et al. [Prevalence of underweight, overweight and obesity in primary school children of Ahvaz city (Iran)]. In: Proceeding of the 9th Iranian Nutritional Congress, Tabriz University (Iran), 2006:117 [in Farsi].

24. Khuwaja S, Selwyn BJ, Shah SM. Prevalence and correlates of stunting among primary school children in rural areas of southern Pakistan. Journal of Tropical Pediatrics, 2005, 51:72-77.

25. Delvarianzadeh $M$, Hosinzadeh $S$, Hosini M. [A study of nutritional state of primary school children and its determinants in Sharoud city (Iran)]. In: Proceeding of the 9th Iranian Nutritional Congress, Tabriz University (Iran), 2006:113 [in Farsi].

26. Kimm SY et al. Relation between the changes in physical activity and body-mass index during adolescence: a multicentre longitudinal study. Lancet, 2005, 366:301-307.

27. Hohepa M, Schofield G, Kolt G. Adolescent obesity and physical inactivity. New Zealand Medical Journal, 2004, 117:1210.

28. Plotnikoff RC, Bercovitz K, Loucaides CA. Physical activity, smoking and obesity among Canadian school youth. Comparison between urban and rural schools. Canadian Journal of Public Health, 2004, 95(6):413-418.

29. Walter $U$ et al. (In)Aktivität in Kindheit und Jugend [Physical (in)activity in childhood and adolescence]. DMW - Deutsche Medizinische Wochenschrift, 2005, 130:2876-2878. 